\title{
Approval of equal rights and gender differences in well-being
}

\author{
Rafael Lalive · Alois Stutzer
}

Received: 10 January 2008 / Accepted: 30 March 2009 /

Published online: 18 June 2009

(C) Springer-Verlag 2009

\begin{abstract}
Women earn less than men but are not less satisfied with life. This paper explores whether norms regarding the appropriate pay for women compared to men may explain these findings. We find that the gender wage gap is smaller where a larger fraction of the citizenry has voted in favor of equal pay. We also find that employed women are less (not more) satisfied with life in liberal communities where the gender wage gap is smaller. These findings suggest that norms regarding the appropriate relative pay of women compared to men are shaping gender differences in well-being.
\end{abstract}

Keywords Gender discrimination - Gender wage gap • Subjective well-being

JEL Classification $\mathrm{I} 31 \cdot \mathrm{J} 70 \cdot \mathrm{Z} 13$

Responsible editor: James Albrecht

R. Lalive $(\varangle)$

Faculty of Business and Economics, University of Lausanne,

Extranef, CH-1015 Lausanne, Switzerland

e-mail: rafael.lalive@unil.ch

\footnotetext{
A. Stutzer

Department of Business and Economics, University of Basel,

Peter Merian-Weg 6, CH-4002 Basel, Switzerland

e-mail: alois.stutzer@unibas.ch
} 
The generality of the male sex cannot yet tolerate the idea of living with an equal.

John Stuart Mill (1869)

\section{Introduction}

It is a well-established statistical finding that women earn less than men on the labor market. ${ }^{1}$ Nevertheless, women do not report significantly lower satisfaction with their life or their job and, in countries like the USA, Great Britain, or Switzerland, they even report higher job satisfaction than men. ${ }^{2}$ This is a puzzle. To the extent that the gender wage gap is thought to be due to discrimination that is perceived as such, one would expect women to experience lower well-being than men, ceteris paribus.

This paper explores whether norms regarding appropriate pay of women compared to men can account for gender differences in salaries and subjective well-being and thus solve the puzzle mentioned above. We do not want to offer a comprehensive theory, but we rather argue that social norms are one factor that has been understudied. In our framework, social norms are internalized and are thus indicative of individual preferences. We follow the argument that there are strong norms handed down from one generation to another that appropriate salaries for men are higher than for women. They are rooted in traditional values favoring gender-specific specialization, giving men priority on the labor market and women priority in the household. Intuitively, the view of men's priority on the labor market leads to higher reference wages of men compared to women. We think of the reference wage as a cognitively relevant standard that affects how people evaluate their income. This reference wage, first, can be understood to affect actual wages because reference pay is important in wage bargaining, where one's reference standard determines the initial offer, as well as the effort invested in negotiating a higher salary. Second, reference standards mediate the effect of actual salaries on individual well-being. As long as both, women and men, get what they expect or ask for, differences in absolute salaries may not result in differences in reported subjective well-being. ${ }^{3}$ However, if our empirical approach captures discrimination, women are expected to report lower subjective well-being in regions with, on average, a larger gender wage gap.

We investigate the extent to which shared norms regarding equal rights are relevant on the labor market by studying a national referendum on an equal rights amendment to the Swiss constitution in 1981. A central proposition of

\footnotetext{
${ }^{1}$ See, e.g., Blau and Kahn (2000), Stanley and Jarrell (1998), and Weichselbaumer and WinterEbmer (2005).

${ }^{2}$ See, e.g., Clark (1997) and Sousa-Poza and Sousa-Poza (2000).

${ }^{3}$ Crosby (1982) calls the same phenomenon the "paradox of the contented female worker" and refers to relative deprivation theory to explain it. Related research is, e.g., discussed in Phelan (1994).
} 
the equal rights amendment was that "women and men shall have the right to equal pay for work of equal value." This referendum thus provides a measure of the degree to which voters believe that the appropriate pay for a woman is equal to that of a man. This proxy measure enables us to identify communities where people challenge the traditional role model and where women demand equality.

We find that there is a smaller gender wage gap for workers in communities where people strongly approved the constitutional amendment on equal rights (liberal communities) than in traditional communities. This finding is consistent with the first implication of a norms-based explanation derived from the notion that women in liberal communities have higher reference standards of what is an appropriate salary than women in more traditional communities.

In order to study the second implication of a norms-based explanation of the gender wage gap, the subjective well-being of women compared to men is analyzed. If the large gender wage gap in traditional communities is due to internalized norms, women in these communities are not expected to report lower subjective well-being than in liberal communities. However, if it is due to discrimination that is perceived as such, the life satisfaction of employed women is expected to be lower in traditional communities compared to liberal ones. Our findings for working women and men indicate that women are not less (but even more) satisfied with their life in traditional compared to liberal communities (while there are no significant differences for men across communities). This finding is again consistent with a framework that incorporates social norms. Furthermore, perceived discrimination of women compared to men is higher (not lower) in liberal than in traditional communities.

Taken together, these findings suggest that the societal approval of equal rights plays a significant role in the labor market success of women compared to men. In interpreting our findings, the possibility of omitted variable biases has, however, to be kept in mind. We therefore study a range of alternative explanations and differential predictions.

This paper does not discuss how the specific social work norms developed. Norms can evolve to justify current practice if, e.g., past discrimination influences current expectations. Social norms may then reflect imbedded effects of past gender discrimination which has been internalized by both women and men. Even though social work norms are seen as part of individuals' preferences and thus relevant for experienced utility, some people might want to override them based on meta preferences for equality.

The remainder of the paper is organized as follows: Section 2 discusses the nature of gender differences in salary entitlements and its consequences for wage bargaining and labor market outcomes. Section 3 proposes a new measure to capture spatial differences in people's beliefs about women's role on the labor market. The empirical relevance of shared beliefs about women having equal rights on the labor market is studied in Sections 4 and 5. We analyze a set of important labor market outcomes as well as four survey measures on reported subjective well-being and perceptions of discrimination. Section 6 offers concluding remarks. 


\section{Norms on the appropriate pay for women and men}

\subsection{Why are there gender-specific norms regarding appropriate pay?}

Salaries are a useful starting point for considering gender differences in labor market success. When market forces determine salaries so that they come close to marginal factor productivity, there is no room for norms on genderspecific appropriate pay. However, the importance of bargaining in wage determination indicates that there is scope for other factors in addition to productivity in determining salaries. While economic thinking has emphasized the role of the outside option in bargaining outcomes, there is ample evidence that social norms and fairness considerations also play an important role in wage setting (e.g., Bewley 1999; Fehr and Gächter 2000).

This paper argues that a particular social pay norm - the belief that women ought to earn as much as men for work of equal value-may affect the outcome of wage bargaining. This gender-specific norm has developed over time. Historically, gender-specific specialization has given men priority on the labor market and women in the household. Men were expected to keep a family, and thus, their appropriate salaries were higher than what they "needed" just for themselves. In contrast, female workers were not expected to keep a family and therefore "needed" less. The early literature in economics noted that

It is notorious that women get lower wages than men because women can live on less, or need less, or are helped out by home supplementation, or have their theatre tickets furnished them by their escorts (Davenport 1919).

Gender-specific specialization was associated with strong gender-specific socialization and occupational segregation. While females were taught to behave in a cooperative, selfless, and nurturing way, males were taught to behave in a competitive and selfish way. These processes led to both sexes having systematically different expectations about what salary is appropriate for women's and men's work. This view is very succinctly expressed by a cotton-spinning mill owner:

[i]f men had from any cause to be employed in the work which women now do, they would undoubtedly get higher wages, though they might not do more or better work; the standard of their wages is higher (cited in Webb 1891, p. 641).

The double standards in appropriate earnings were explicitly studied among 200 white adults in Baltimore (Jasso and Webster 1997). Based on the vignette technique, they find that women as well as men considered appropriate earnings to be lower for women than for men (with similar age and same education and occupation). The female/male ratio in the "fair" gender wage gap is estimated at 0.85 for men and 0.88 for women. These results are due to a lower base level of the fair salaries as well as lower returns to schooling 
for women than for men. Complementary evidence is from survey studies with small samples drawn from the college student population. In one study (Major et al. 1984), 76 undergraduates had to determine what they thought would be a fair compensation for a fixed amount of work. The young women in the sample paid themselves less money than the young men did. In a second study by the same authors, 40 women and 40 men received a payment first and were then asked to do as much work as they thought appropriate for the amount they had received. Women worked longer, made fewer mistakes, and had a higher output. Differences in pay standards were also found for 126 people who determined either their own salary or the salary of another person. Women paid themselves less than men did and even less than what they paid other women (Callahan-Levy and Messe 1979). In another study (Bylsma and Major 1992), 203 undergraduates indicated how much they deserved to be paid in nine different employment scenarios. The earnings women felt that they deserved were lower than men's earnings. It is also found that women's ratings of their performance and their pay satisfaction are more influenced by comparing themselves with other women than with men (Bylsma and Major 1994).

Arguably, norms about appropriate pay are likely to change only slowly over time. Individual pay negotiations are typically based on limited knowledge of other workers' pay. The tendency to interact more frequently with coworkers of the same gender implies that information about male coworkers' pay has a limited impact on the wage negotiated by a woman. Moreover, information about gender differences in pay in liberal regions is unlikely to affect conservative regions due to limited mobility of workers. In our analysis, this suggests that norms about women's and men's separate roles on the labor market and about appropriate salaries prevailing in 1981 still hold today to some extent and imply gender-specific differences in compensation.

However, there are women who do not share the norms anymore and some of them have been active in the women's movement, have engaged in the introduction of equal rights legislation, advanced pay transparency, or have stood up for institutions that make job and family life compatible. There is also a rethinking occurring in the minds of men and some giving up of traditional roles and norms. Thus, the extent to which the traditional norms are shared varies substantially between people, but also between countries, regions, and even small neighboring communities.

\subsection{What are the consequences of gender-specific appropriate pay norms?}

To the extent that women as well as men think that women deserve lower pay, women can be expected to negotiate in a systematically different way than men do. In fact, there is now substantial evidence that women ask for less than men, or do not ask at all in pay negotiations (Babcock and Laschever 2003; Riley and McGinn 2002; Säve-Söderbergh 2006; see also Stuhlmacher and Walters 1999 for a meta-analysis on gender differences in negotiation outcomes). Babcock and Laschever, for example, report from a survey in the USA that $20 \%$ of 
women said they never negotiated. For most women, the most recent pay negotiation goes twice as far back as for most men. Women's reluctance to negotiate is reinforced by other parties in the bargaining process. Women who ask for more or promote themselves often suffer social reprisals because they violate the gender prescription of being modest (e.g., Wade 2001). These gender-specific beliefs about appropriate behavior and payoffs are also found in laboratory experiments with stylized bargaining situations. In ultimatum games, it is found that both women and men offer less to women, and both women and men choose higher minimum acceptable offers when the proposer is a woman (Solnick 2001).

A straightforward prediction of women making lower initial offers in salary negotiations and negotiating less often is that they earn less than men for equal work. ${ }^{4}$ There is a substantial literature in labor economics studying gender differences in wages. A key difficulty in this research, however, is the identification of the causal mechanisms leading women to earn less than men for seemingly equal work (Altonji and Blank 1999). Many findings that are usually regarded as discrimination by employers, fellow male employees, and customers, or as statistical discrimination, can be well understood in a framework of norms about gender-specific appropriate salaries. Examples are findings about the gender wage gap under collective bargaining (e.g., Blau and Kahn 2003). In particular, as the position of female employees' in collective salary negotiations is strengthened, lower gender differences compared to individual bargaining might indicate that gender specific appropriate salaries are partly overcome. Another set of findings is about the effect of product market competition on the gender wage gap. In a study about the US banking sector, e.g., liberalization is argued to have reduced the possibilities for employer discrimination (Black and Strahan 2001). An alternative interpretation is that as the pot of money to be distributed among employees became smaller, it was no longer possible to satisfy men's relatively higher aspirations in negotiations about their compensation. However, the strength of social norms about gender differences in appropriate salaries has, as far as we are aware, never been measured explicitly in order to be able to test such alternative explanations more closely.

\section{Measuring norms regarding appropriate pay}

We propose measuring the norm that women's appropriate salaries are not different than men's using the voting outcome on an amendment to the Swiss constitution. In January 1975, the fourth national congress of women in Switzerland decided to launch a popular initiative postulating equal rights for

\footnotetext{
${ }^{4}$ Norms about women's and men's role on the labor market do not only affect the outcomes of salary negotiations but also decisions about promotion (for related work on glass ceiling, see, e.g., Albrecht et al. 2003) and advanced training or shared expectations about appropriate effort on the job.
} 
women and men. Up until then, article 4 of the Swiss constitution held that "all human beings are equal before the law". Skeptics suggested that legal practice only ensured that all women were equal and all men were equal, but no woman was a man's equal in the eyes of the law. Note that Switzerland is quite conservative regarding women's rights. For instance, the Swiss government did not ratify Charter 100 of the ILO, demanding equal rights for women and men, until 1972.

The initiative proposed amending the constitution by an article that listed in detail the specific areas and the respective rights that should be made law. In December 1975, the committee launching the popular initiative had collected the number of signatures required to force the Swiss government to schedule the initiative. The parliament decided to work out a counter proposal reading as follows:

Men and women have equal rights. Legislation shall ensure legal equality, particularly in the areas of family, education and work. Men and women shall have the right to equal pay for work of equal value.

The committee who launched the initiative decided to withdraw the original version of the amendment.

The constitutional amendment covers three important areas: Equality within the family was an essential ingredient to the cause of Swiss women because the prevailing family law stipulated the husband as being the head of the family and being the sole actor to represent the family outside. Equality in education was deemed an important cause because school curricula were reflecting the old view that girls should be taught the skills of running a household, as opposed to boys who should be able to support the household. Thus, from secondary school onwards, girls tended to be taught how to knit and cook, whereas boys perfected their skills in mathematics. The area of market work formed an essential pillar of the constitutional amendment because women earned, on average, $30 \%$ less than men according to newspaper articles of that time. It is noteworthy that in contrast to the general norms stipulated with respect to family and education, the amendment contains the explicit directive that women must earn the same money for work of equal value. Thus, this third requirement was to improve the legal situation of women immediately after the vote had been cast. ${ }^{5}$

The public debate in the newspapers focused mainly on two issues. "Will a 'yes' to this amendment mean the end of the family?" 6 and "Equal work-

\footnotetext{
${ }^{5}$ It was understood at the time that primarily, the private sector would be affected by this vote. The public sector had been covered by the ILO equal rights agreement no. 100 that the Swiss government had ratified in 1972 and by a federal law passed in 1977. The amendment did not directly invalidate all contracts between employers and workers that stipulated different pay for equal work. Instead, each contract had to be reviewed separately by the court in order to determine violation of the constitution (Neue Zürcher Zeitung, July 30, 1981).

${ }^{6}$ Headline of an article in the newspaper Blick, June 3, 1981.
} 
but the wage is different."7 The issue of the implications for the family has to be seen against the backdrop of the 1968 revolution. Conservative thinkers argued that this amendment might be used to create the legal framework that would destroy the "main pillar of society." The second issue of unequal pay was addressed in several ways. First, some newspapers focused on minimum wages in identical occupations. For instance, it was found that the minimum wage for a male sales clerk was $1,900 \mathrm{CHF} /$ month, whereas a female sales clerk earned only 1,640 CHF/month. Second, a dissertation at the University of Berne investigating unequal pay between women and men got a lot of press coverage (Reis 1988). Relying on unusually rich data regarding work input, this dissertation found that women did indeed earn less than men, that the expected job duration of women was shorter, representation of women in unions was lower, and that discrimination might contribute to this differential pay for equal work. This shows that voters were indeed confronted with the issue that women were earning less than men.

On June 14, 1981, Swiss voters had to decide whether they would like to amend the Swiss constitution to reflect not only equality of human beings in general but equality of women and men in particular. A total of 707,702 voters (or $60.2 \%$ of the electorate) and 17 cantons voted in favor of the amendment, while 525,885 voters and nine cantons opposed the amendment- the initiative proved to be successful. ${ }^{8}$ In the exit poll, the main reasons in favor of the amendment were "equal pay for work of equal value," "equal rights," and "women are worth as much as men" reported by roughly $70 \%$ of the voters interviewed. The remaining $30 \%$ of voters argued in favor of the amendment because it brought advanced gender equality in the family and in education.

This shows that the vote indeed reflects the extent to which voters agree with the norm that women should earn what men do if they do the same work. ${ }^{9}$

Figure 1 shows the cross-sectional distribution of approval of equal rights across 2,896 Swiss communities, with lighter shading reflecting a higher proportion of people approving of equal rights. On the one hand, the western and the southeastern parts of Switzerland, as well as the area around Zurich, tended to favor the constitutional amendment strongly. On the other hand, a dark belt of communities stretching from the southwest to the northeast of Switzerland expressed their disapproval of the amendment. There is a surprising number of communities in which not only men but also a significant proportion of women must have rejected the amendment. This suggests that not only one's own material well-being (instrumental voting) but rather the shared beliefs

\footnotetext{
${ }^{7}$ Headline of an article in the newspaper Luzerner Neuste Nachrichten, June 4, 1981.

${ }^{8} \mathrm{~A}$ constitutional amendment has to be accepted by both the majority of people and the majority of cantons.

${ }^{9}$ In reaction to the vote, the Swiss employer's association printed a booklet to be distributed to its members containing, among other things, the reasons for unequal pay between women and men. "There is scientific proof that women are $30 \%$ [note that this figure coincides exactly with the gender wage differential at that time] less productive than men. This finding is based on studies that study the oxygen intake capacity of male and female subjects."
} 


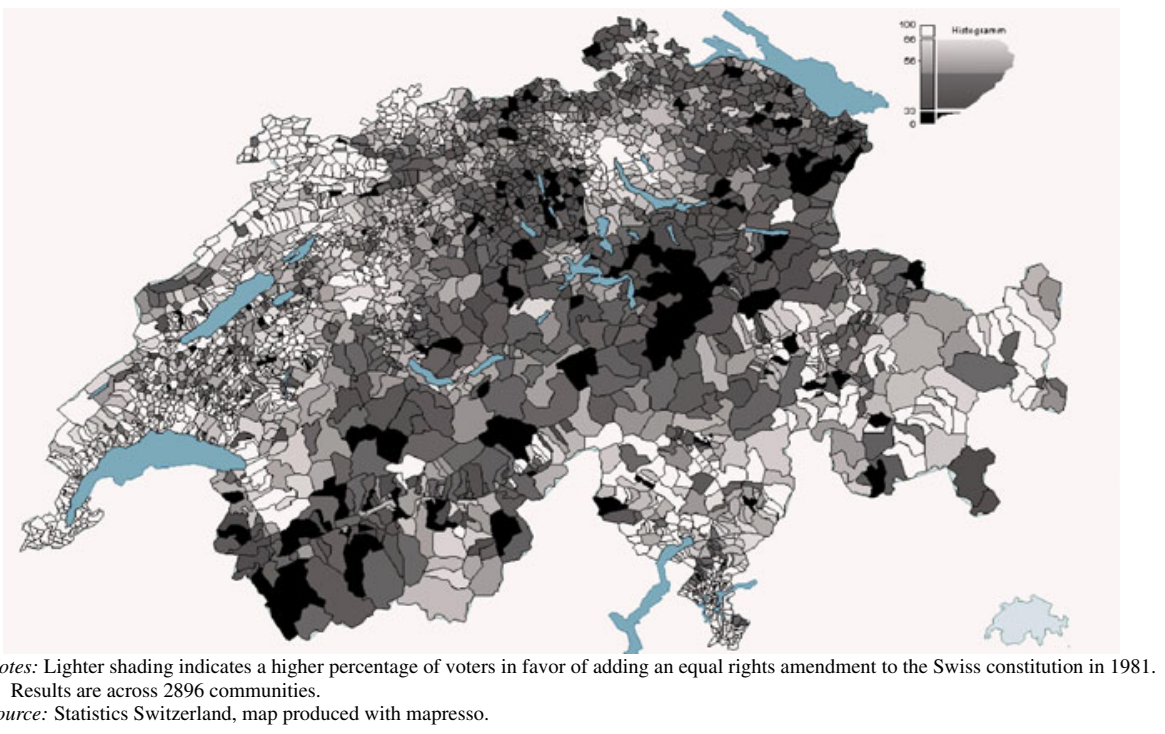

Fig. 1 Approval of the constitutional amendment on equal rights in Switzerland, 1981

about the appropriate pay and position of women were important in the voting decision (expressive voting). ${ }^{10}$

In the empirical analysis below, we take the voting result to measure the extent to which people share the view that women should have the same rights in all areas of life and the same entitlements on the labor market as men. ${ }^{11}$ We rely on the vote as a proxy that captures the views of voters in 1981, which we then merge with information on labor market and subjective wellbeing outcomes at the end of the twentieth century. This means that we can investigate both a direct channel that runs from individual values and norms to well-being (for the older cohorts) as well as an indirect inter-generational

\footnotetext{
${ }^{10}$ It would, of course, also be possible to develop an argument why women who voted "no" followed their material self-interest (instrumental voting). Intra-household bargaining theory, e.g., suggests that a woman not working in the labor market is more concerned with the impact of the referendum on her husband's salary than her own potential salary in the future. To the extent that the amendment leads to overall wage pressure, she would find it in her material selfinterest to vote against equal pay. However, the motives for approval or disapproval stated in the survey conducted immediately after the vote do not align with considerations following from intra-household bargaining theory.

${ }^{11}$ Note that it is not possible to rely on different votes to find an equally convincing proxy for the social pay norm. Possible candidates for different votes include the national referendums on extending suffrage to women held in 1959 (rejection) and 1971 (approval). These referendums capture more generally than the present popular initiative the notion of political equality between men and women. As an attractive alternative, surveys tend to focus more directly on values. However, it is usually not possible to rely on them to measure the norms that prevail within communities, as there are not a sufficient number of observations for any communities other than a few big cities.
} 
channel, whereby we study the role of the parents' views for the children's outcomes (for the younger cohorts). Of course, merging past information on norms with current information on outcomes implies measurement error and leads to lower bound estimates. However, it is likely that individuals, who were liberally minded 20 years ago, still tend to live in liberal communities. Moreover, choosing to live in communities where people share similar norms facilitates the analysis rather than hampers it. ${ }^{12}$

For a social work norm to be relevant in wage determination today, it is, of course, necessary that gender differences with respect to appropriate pay still exist. Based on the vignette technique, ${ }^{13}$ Jann (2003) asks a random subset of a total of 531 survey respondents in Switzerland whether they think that 4,000 CHF/month (approximately US \$2,700) is too low or too high for Mrs. Smith (on an 11-point scale). A randomly chosen second set of survey respondents rate whether the same income is appropriate for Mr. Smith. Results indicate that survey respondents think that 4,000 CHF/month is much too low for Mr. Smith in comparison with Mrs. Smith. Thus, there is still evidence for gender-specific differences in appropriate pay today. ${ }^{14}$

\section{Norms on appropriate pay and the gender wage gap}

Social norms about women's role on the labor market and shared beliefs about their appropriate salaries are expected to be important determinants of actual wages. We study this claim based on our proxy measure for equal rights and a large data set about individuals' labor market outcomes. We rely on the first 13 waves of the Swiss Labor Force Survey (SLFS). This rotating panel survey started in 1991. Interviews are conducted each year in springtime. The information gathered is primarily used to generate up-to-date information on the state of the Swiss labor market. Since the SLFS contains information on the community of residence, we can merge information on the percentage of voters who approved the equal rights amendment in 1981. In total, there are 2,896 communities (bottom-level political jurisdictions) in Switzerland, ranging in size from several hundred inhabitants to up to more than 300,000 inhabitants.

\footnotetext{
${ }^{12}$ Note that the information about shared local norms is news only for us as statisticians. However, these norms have been prevalent and at work in these communities for years. What we observe in outcomes with regard to the gender wage gap (Section 4) and the gender subjective well-being gap (Section 5) is not the response to the referendum, i.e., it is not a reaction to the referendum in terms of an information revelation to fellow citizens.

${ }^{13}$ Jann (2003) applies the same technique as used in the work by Jasso and Webster cited in Section 2.1.

${ }^{14}$ Previous research shows that the ratio of the earnings of women relative to men is lowest in Switzerland in comparison with the USA and six other OECD countries (Blau and Kahn 1992). The unexplained component of the wage differential is especially high for workers with low education (Bonjour and Gerfin 2001). Flückiger and Ramirez (2000) analyze the changes in the wage structure between men and women from 1994 to 1996.
} 

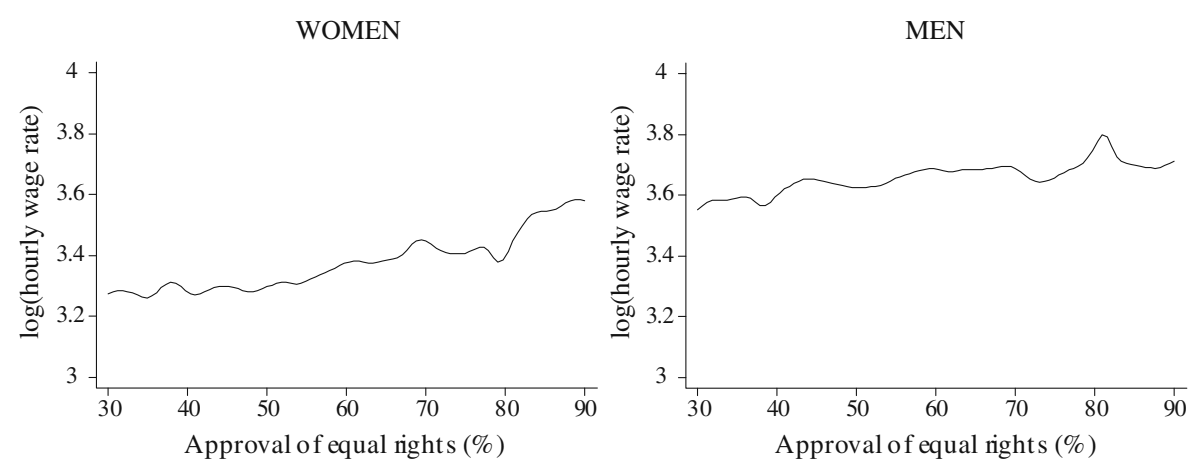

Note: Kernel regressions (gaussian kernel).

Source: Swiss Labor Force Survey, 1991-2003, own calculations.

Fig. 2 Approval of equal rights and wages

The analysis concentrates on all observations with valid information on income, contractual hours of work, and additional information concerning human capital and demographic information. This yields a total of 117,878 observations covering 73,526 individuals living in 2,498 different communities.

Figure 2 presents a kernel regression of the log of the hourly rate of pay on the approval of equal rights. ${ }^{15}$ There are two striking features in this figure. First, women's wages tend to be much lower than men's wages. Second, there is a marked increase in the wage rate of women in line with equal rights being approved. In contrast, the wage rate of men is much less sensitive to the voting outcome. This is consistent with differences in social work norms being reflected in labor market outcomes.

Table 1 presents additional descriptive evidence on the relevance of genderspecific norms regarding the labor market position of women compared to men. In addition to the log of the hourly rate of pay, we concentrate on three labor market outcomes: years of schooling, years of actual experience, and years of tenure with the current employer. Actual experience is defined in the SLFS as the duration of employment since the last interruption in employment that lasted longer than 6 months. It is crucial to measure actual experience, since this human capital input measure reflects more adequately than potential experience (i.e., age minus time spent in education) the differential attachment to the labor market between women and men.

\footnotetext{
${ }^{15}$ The hourly wage rate is calculated by dividing annual earnings by annual hours. We use a Gaussian kernel with default bandwidth in kernreg1.ado for STATA. The "blip" in wages for women and men at $80 \%$ voting in favor for equal rights is due to low density of observations at $80 \%$ and under-smoothing produced by the default bandwidth.
} 


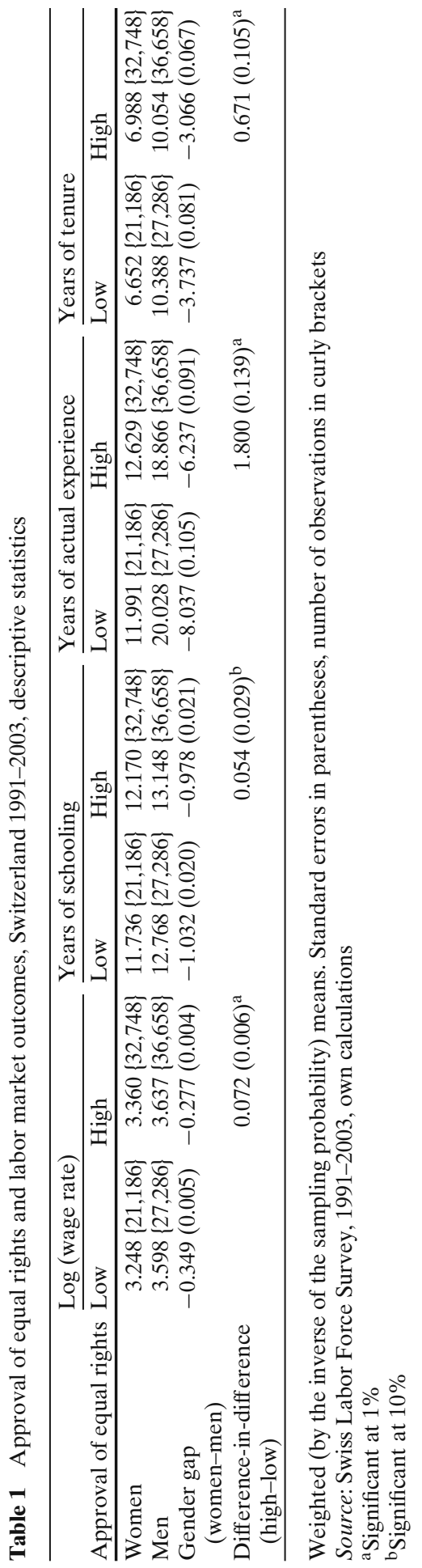


The first two columns in Table 1 report gender differences in the weighted mean of the log of the hourly rate of pay. ${ }^{16}$ Women who live in communities with approval rates below average $(<60 \%)$ earn $30 \%(=(\exp (-0.349)-1) \times$ $100)$ less than men. The corresponding gender wage gap is $24 \%$ in communities with approval of equal rights above average (>60\%). Thus, regional differences in approval of equal rights are correlated statistically and economically significantly with the gender wage differential. The higher the proportion of people voting in favor of equal rights in 1981, the lower is the wage gap between women and men in our sample from 1991 to 2003. Columns 3 to 8 in Table 1 perform a similar analysis for the number of years of schooling, number of years of work experience, and number of years of tenure. The idea is that in communities that hold the view that women should earn equal pay for equal work, women may have stronger incentives to invest in human capital. The descriptive evidence in Table 1 weakly suggests that women tend to have a smaller educational disadvantage compared to men in communities with approval rates exceeding $60 \%$. With respect to work experience, we find that women have 8 years less actual experience than men in conservative communities. The corresponding figure in liberal communities is only 6 years. Interestingly, this result does not originate primarily from higher investment of women in work experience but also from weaker investment of men in liberal communities. The last outcome, the number of years of tenure with the current employer, is studied in columns 7 and 8 . We find that women tend to have shorter tenure representing lower investments in specific human capital than men and that this disadvantage tends to be much lower in liberal areas than in conservative areas. In contrast to the results for work experience, we find here that this effect originates primarily from differences in women's investments in specific human capital.

Table 2 performs the same difference-in-differences analysis in a regression setting. All regressions control for nationality, marital status, part-time status, canton of residence effects, and time effects. In addition, results for the wage rate include number of years of schooling, number of years of work experience (and its square), and number of years of tenure (and its square) as control variables (see Table 6 in Appendix for results regarding the control variables). Robust standard errors are reported, adjusted for clustering within communities. The fraction approving of equal rights is standardized, i.e., demeaned and divided by the standard deviation. Thus, the coefficient for "female" in column 1 of Table 2 measures the gender wage differential in the community with average approval of equal rights $(60 \%)$, and the coefficient for "approval of equal rights" gives the change in the log of the hourly rate of pay associated with an increase by one standard deviation (8\%) for men. Results show that women's wage rates are $13.8 \%$ lower than men's wages in the average

\footnotetext{
${ }^{16} \mathrm{We}$ use the inverse of the sampling probability as weights because some waves of the SLFS tend to oversample specific areas of Switzerland. Weighting effectively ensures that the results are representative at the national level.
} 
Table 2 Approval of equal rights and labor market outcomes, Switzerland 1991-2003, partial correlations

\begin{tabular}{lllll}
\hline & Log (wage rate) & Years of schooling & $\begin{array}{l}\text { Years of actual } \\
\text { experience }\end{array}$ & Years of tenure \\
\hline $\begin{array}{l}\text { Female } \\
\begin{array}{c}\text { Approval of } \\
\text { equal rights }\end{array}\end{array}$ & $-0.138(0.006)^{\mathrm{b}}$ & $-0.950(0.039)^{\mathrm{b}}$ & $-4.828(0.218)^{\mathrm{b}}$ & $-2.164(0.120)^{\mathrm{b}}$ \\
$\begin{array}{c}\text { Female } \times \text { approval } \\
\text { of equal rights }\end{array}$ & $0.024(0.006)^{\mathrm{b}}$ & $0.296(0.045)^{\mathrm{b}}$ & $-0.012(0.163)$ & $0.078(0.115)$ \\
$\begin{array}{l}\text { Individual } \\
\text { characteristics }\end{array}$ & Yes & $0.008(0.036)$ & $0.864(0.175)^{\mathrm{b}}$ & $0.392(0.120)^{\mathrm{b}}$ \\
$\begin{array}{l}\text { Observations } \\
R^{2}\end{array}$ & 117,878 & Yes & Yes & Yes \\
\hline
\end{tabular}

Weighted (by the inverse of the sampling probability) ordinary least squares estimations. Robust standard errors in parentheses (adjusted for clustering within communities). Individual characteristics are: years of schooling, years of actual experience (and its square), years of tenure (and its square), nationality, martial status, part-time employment status, canton, and time dummies for results regarding the wage rate. Years of schooling, years of actual experience, and years of tenure are omitted from the three remaining estimates

Source: Swiss Labor Force Survey, 1991-2003, own calculations

${ }^{a}$ The approval rate of the equal rights amendment is standardized with a mean of zero and standard deviation equal to one

${ }^{\mathrm{b}}$ Significant at $1 \%$

community. This is a substantially smaller gender wage gap than the $30 \%$ reported in 1981, first because it narrowed over time and second because we control for differences in education, experience, and tenure between women and men. Men's wage rates increase by $3.5 \%$ when the approval of equal rights increases by one standard deviation. ${ }^{17}$ This may be due to the fact that approval of equal rights is low in rural areas (with relatively lower wages) and high in cities (with relatively higher wages). The interaction term "female $\times$ approval of equal rights" indicates that the wage rate of women tends to increase even more than for men in line with approval of equal rights. For an increase by one standard deviation, the gender wage gap is reduced by 2.4 percentage points. The coefficient is strongly significant in the statistical sense. More importantly, the result indicates that the mean gender wage gap is narrowed by as much as one sixth due to an increase of one standard deviation in the approval of equal pay for equal work. ${ }^{18}$

This latter result is not driven by differential occupational sorting of women and men across space. In a first robustness check, detailed year-specific occupation effects (three-digit occupational classification) are added as control

\footnotetext{
${ }^{17}$ This result is conditional on potential regional differences in schooling, work experience, and tenure.

${ }^{18}$ Differences in prices across communities do not invalidate this conclusion, since prices are identical for women and men across communities.
} 
variables to the basic regression in Table 2 column 1 (not shown). ${ }^{19}$ Similar to the baseline regression, we find that a one standard deviation increase in the approval of equal rights reduces the gender wage gap by about one sixth. Interestingly, accounting for occupational differences decreases the coefficient for the partial correlation between the approval of equal rights and the wages of men (from $3.5 \%$ to $1.0 \%$ ) but increases the extent to which the wage gap narrows (from 2.4 percentage points to 3.0 percentage points). This result indicates that there is geographical sorting into occupations that can explain regional variation in wages. However, there is no evidence for substantive spatial differences in gender-specific occupational sorting.

The second column in Table 2 reports results for number of years of schooling. In contrast to the descriptive evidence in Table 1, we do not find a significant correlation of the gender gap in schooling with the approval of equal rights. However, for both work experience and tenure with the current employer, we find a significant and quantitatively important reduction in the female disadvantage associated with higher approval of equal rights. Results suggest that up to one sixth or 0.86 years ( 0.39 years) of the average difference in work experience (tenure) of 4.83 years (2.16 years) between women and men disappears due to a one standard deviation increase in the approval of equal rights. One interpretation of this finding is that liberal views regarding the pay of women and men are also increasing the incentives to invest in general and firm-specific human capital.

It is interesting to compare the whole narrowing of the gender wage gap across regions (when no productivity characteristics are taken into account) with the extent that the gender wage gap narrows, controlling for human capital, experience, and tenure. In an unconditional regression of the wage rate on canton effects and time effects (not shown), we find that the gender wage gap narrows by 4.9 percentage points due to an increase by one standard deviation in the share of people approving equal rights. In contrast, the first column in Table 2 shows that conditional on observed characteristics, the gender wage gap narrows by 2.4 percentage points due to an increase by one standard deviation in the approval rate. The total effect is thus about twice as strong as the conditional effect. This suggests that the social norm that women should earn as much as men may lead to an indirect increase in the wage rate (via gender differences in human capital investment) of about the same order of magnitude as the direct effect of this belief on wages (via gender differences in bargaining behavior).

Table 3 investigates the sensitivity of our result for wages in six subsamples. Communities in Switzerland differ with respect to size and population density. Recent work on monopsony in labor market argues that in rural areas, employers might have comparably more monopsony power than in areas with higher density of jobs, like in cities (Manning 2003). The monopsony wage is lower for groups who react less elastically to wages earned with the current employer. If

\footnotetext{
${ }^{19}$ Results not shown in the text are available on request from the authors.
} 


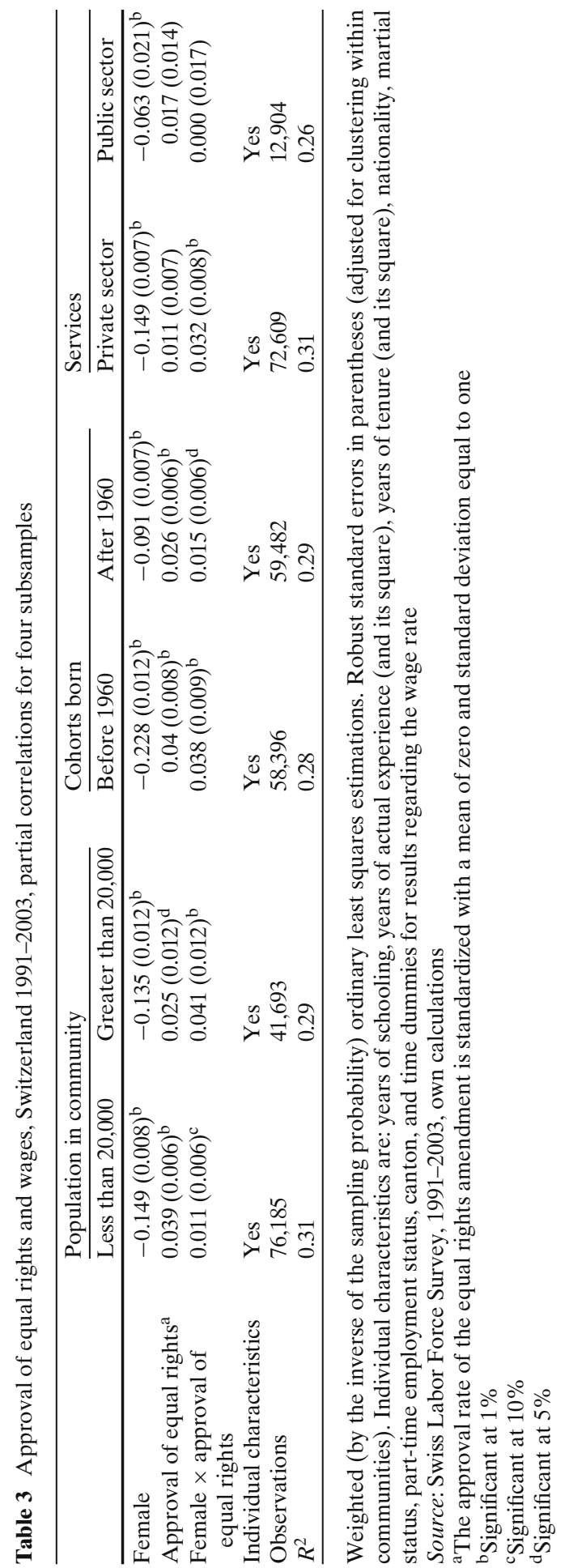


separation elasticities are lower for women than for men, ${ }^{20}$ women will earn less in rural areas than men compared to more densely populated areas. ${ }^{21}$ Moreover, approval of equal rights is higher in cities than in rural areas. This suggests that the main result reported in Table 2 might be spurious. Differences in wage settings with respect to the size of the community instead of the appropriate pay norm are driving the results. We address this first issue by performing a separate analysis for communities with a population of less than 20,000 inhabitants (in 1990) and communities with a population of 20,000 inhabitants or more. First, we find that women's wages tend to be lower than men's wages in both samples by a similar magnitude, the difference amounting to about.14 log points (columns 1 and 2 in Table 3). Second, in the sample of large communities, there is a strong and statistically significant increase in the wages earned by women compared to the wages earned by men in more liberal communities. This means that the main result reported in Table 2 cannot be rationalized via differences in wage settings across urban and rural communities. $^{22}$

The second analysis contrasts cohorts born before 1960, who presumably voted in 1981, and cohorts born after 1960, who were not allowed to vote in $1981 .^{23}$ This split in the sample allows studying the inter-generational transmission of social norms. People in the younger cohorts are exposed to norms that overall emphasize gender equality more than in the past (for a given crosssectional variation). Accordingly, we expect that differences in the gender wage gap are more pronounced among older cohorts than among younger cohorts. ${ }^{24}$ In fact, results indicate that for younger cohorts, there are smaller norm effects than for older cohorts. However, in relation to the gender wage gap in the average community, the norm effect is of the same relative magnitude across cohorts. A one standard deviation increase in the approval of equal rights is estimated to decrease the gender wage gap by one sixth. This suggests that social norms regarding appropriate pay for women compared to men are also relevant in cohorts that have entered the labor market only recently.

\footnotetext{
${ }^{20}$ Ransom and Oaxaca (2005) calculate based on gender differences in the elasticity of separations with respect to the wage earned in the current job that the elasticities of labor supply to the firm are about 3.5 for men and about 2.7 for women.

${ }^{21} \mathrm{~A}$ second argument in favor of contrasting rural areas with cities rests on the presumption that the fraction of jobs that is tailored entirely to men or women is higher in rural areas than in cities. ${ }^{22}$ The fact that the interaction term "female $\times$ approval of equal rights" is larger for cities than for relatively small communities may indicate that place of work and place of residence coincides to a larger extent in the former than in the latter. Moreover, expressed norms in 1981 may be a less accurate proxy for norms to today in small communities due to differences in migration.

${ }^{23}$ The minimum age for voting at the national level was 20 in 1981.

${ }^{24}$ Alternatively, it is likely that individuals, who were relatively old in 1981 , are more likely to still be living in the same community than younger individuals. Thus, the voting proxy for the social norms regarding the position of women on the labor market may be better for older cohorts than for younger cohorts. This sample split also allows assessing whether reverse causality is biasing the results. Young women's attitudes are not measured in the voting proxy of the social norm. For young women, the norm measure therefore reflects the norms of the neighborhood that they have been exposed to.
} 
The third comparison distinguishes the private service sector from the public sector (education and public administration). ${ }^{25}$ Comparing these two sectors is motivated by the fact that wage bargaining is less common in the public sector and that the public sector was covered by legislation writing down the equality of pay between women and men as early as $1977 .{ }^{26}$ In contrast, it proved to be very difficult to actually substantiate the claim that equal pay for equal work was violated in the private service sector.

Results for the private sector indicate that the gender wage gap in the average community amounts to almost $15 \%$ and that the gender wage gap is lower in communities that have voted more strongly in favor of the equal rights amendment (column 5 in Table 3). In contrast, the gender wage gap in the public sector is much smaller (about $6.3 \%$ ) and this gap is independent of the approval of equal rights. This result is in line with standardized compensation rules and legislation equalizing relative pay between women and men across communities, irrespective of the prevailing social pay norm. ${ }^{27}$

Our findings provoke some economic follow-up questions and empirical concerns that we would like to briefly mention. First, one might ask why do all women not move to liberal areas if differences in outcomes actually reflect causal effects of social norms on economic well-being. If economic wellbeing were all individuals cared about, they probably would. Yet we will study in the following section to what extent differences in economic well-being are in line with differences in overall subjective well-being. A second issue arises with using the voting result as a proxy for the social norm. As argued earlier, the respective social norms are seen to be internalized, learnt by the individuals during the formative years at home or at school. This implies that the voting measure is likely to be a better proxy for internalized norms regarding appropriate pay for individuals who stay in their community compared to individuals who move during the sample period. Indeed, we find that the wage gap between women and men narrows slightly more strongly for stayers than for movers (results not shown). Third, the results for the gender wage gap could be explained in terms of a closely related norm, namely, that women should not go for paid work. The women observed on the labor market in

\footnotetext{
${ }^{25}$ Note that these results focus on services because the type of work performed by women and men across service industries is more homogenous than across all industries. Results for the remaining 32,365 observations are similar to the results for the private sector services industries (not shown). ${ }^{26}$ On October 12, 1977, the Swiss federal court ruled that female teachers in the canton of Neuchâtel have to be granted the same salary scale as their male colleagues.

${ }^{27}$ The fact that women are, on average, paid less than men in the public sector suggests that unmeasured productive characteristics are important. Unfortunately, it is not possible to address the concern with unmeasured productive characteristics with information on regional mobility because mobility is endogenous. However, note that sorting of unproductive (relative to women) men into liberal areas (or vice versa) is at odds with the evidence in Table 3. We find that there is no correlation of the gender wage gap with voting in industries where appropriate pay norms are unimportant in affecting pay policies, i.e., public sector service industries. This suggests that gender differences in unobserved productivity are unlikely to explain the fact that gender wage gaps are smaller in liberal areas compared to conservative areas.
} 
more traditional communities are those who are better off working-despite the social pressure - than staying at home (high disutility of staying at home). These women are in a weaker bargaining position and end up with a relatively lower wage. It is not possible to discriminate between the two norm-based explanations from wage regressions alone. However, the alternative explanation can be addressed based on our data on women's subjective well-being (in the next section). Working women are expected to report lower life satisfaction in more traditional communities than in more liberal communities (because of the social sanctions and the lower work compensation). Fourth, the questions arise why firms do not concentrate on hiring women in traditional communities exploiting the situation and thus whether the empirical finding can reflect an equilibrium (following the classical reasoning of Becker 1976). We think that market forces in fact partly wipe out differences in compensation due to social work norms. However, we also think that there are still "sufficient" market imperfections that norm effects can put a wedge between productivity and compensation.

The empirical concerns relate to the inherent problems with cross-section analyses. First, it is not possible to rule out that unobserved gender differences in productivity or in the demand of work place amenities are driving our results. However, an alternative explanation based on these factors is difficult to align with the differential results for location of residence, cohorts, and industries. Second, it is possible that local differences in compensation for reasons that are not related to norms might have affected voting decisions. Settling this issue of omitted variable bias would require estimations with valid instruments. So far, we do not see this as a feasible task in the current setting. Instead, we test whether reported subjective well-being is consistent with the idea that norms regarding appropriate pay explain gender differences in compensation.

\section{Norms on appropriate pay and subjective well-being}

Subjective measures of people's well-being offer a complementary possibility for studying the consequences of social norms about the role of women on the labor market. Traditional economic reasoning would predict that women who experience a larger gender wage gap also experience relative lower utility than men. However, if social norms are affecting salaries and the gender wage gap, women in traditional areas need not feel worse off than women in liberal areas because women in traditional areas have lower salary expectations to begin with.

Subjective well-being is captured by measures of reported happiness, satisfaction with life, or satisfaction with particular life domains, like one's job. These measures of reported subjective well-being passed a series of validation exercises and seem to significantly correlate with true positive inner feelings (see Frey and Stutzer 2002a, b for introductions to the economics of happiness and references to the validation literature). Based on measures of subjective 
and psychological well-being, there is substantial research on gender differences in well-being (for a review, see Nolen-Hoeksema and Rusting 1999). Recently, striking downward trends in women's happiness (see Blanchflower and Oswald 2004 for the USA), women's life satisfaction (see Stevenson and Wolfers 2007 for a series of European countries), and women's job satisfaction (see Sousa-Poza and Sousa-Poza 2003 for Great Britain) have been reported and have-so far-remained unexplained. Here, measures of reported subjective well-being are taken as a new opportunity for understanding the effect of social norms on individual welfare in a cross-section setting. ${ }^{28}$ However, in future research, the framework could be extended in order to test whether long-term trends in women's subjective well-being relate to changes in social norms. It is important to note that this approach rests upon the assumption that there is not a norm-dependent response frame when people answer the question on their satisfaction with life. Otherwise, the observed differences across communities cannot be interpreted as differences in individual welfare. ${ }^{29}$ Moreover, measures of subjective well-being allow a direct empirical analysis of two related issues:

First, in the context of discrimination, it is misleading to only look at the outcomes in order to make welfare judgments. It is most likely that discrimination per se, i.e., how women are treated, has negative effects on women's subjective well-being. ${ }^{30}$

Second, subjective well-being may be affected by reference standards. According to standard economics, income enters individuals' utility function in an absolute sense. Consistent with the important role of standards of appropriate salaries in negotiation behavior, however, reference standards also affect the subjective evaluation of labor market outcomes. People judge their situation relative to their aspirations or some reference standard, and it is the discrepancy between this reference standard and the actual outcome that determines people's subjective well-being. In a direct test of this concept of relative utility, higher income aspirations are related to lower life satisfaction ceteris paribus (Stutzer 2004). ${ }^{31}$ Norms prescribing females' wages to be lower than

\footnotetext{
${ }^{28}$ In a previous study, the role of the social norm to live by one's own earnings in unemployed people's life satisfaction has been analyzed. It has been found that the stronger the social norm to work, the less satisfied unemployed people are with their life (Stutzer and Lalive 2004).

${ }^{29}$ Instead, we would observe what Kahneman (2000) called a "satisfaction treadmill": people report constant well-being even though their "true" individual welfare increases with a higher material living standard (here, a lower gender wage gap). However, if in more liberal communities women's aspirations increase, their "improved" circumstances need not to translate into higher "true" individual welfare as women experience a "hedonic treadmill effect." However, we do not think that differences in the response frame hide working women's suffering due to discrimination in more traditional communities, as we see consistent patterns of evidence across four measures.

${ }^{30}$ This can be understood as procedural disutility (see Frey et al. 2004 for the concept of procedural utility) that affects women's well-being beyond narrow economic outcomes such as wages.

${ }^{31}$ In a study of 5,000 British workers, Clark and Oswald (1996) formed the reference income as the average income of persons with the same labor market characteristics. They conclude that the higher the income of the reference group, the less satisfied people are with their job.
} 
men's wages can thus be expected to positively affect women's subjective wellbeing because their lower salary standards reduce the gap between expected and actual income (Clark 1997). This mechanism could explain the finding mentioned in Section 1 that in most countries, women do not report lower subjective well-being than men despite gender wage gaps persisting.

We approach the question using a second data set: the Swiss Household Panel (SHP). We use the first three available waves from 1999 to 2001 as our testing strategy is for a cross-section design. The SHP is a representative survey for Switzerland and contains roughly 7,000 individual observations per wave from roughly 1,000 different communities. In addition to standard socioeconomic characteristics, it includes a question about job satisfaction in 1999, a question about satisfaction with life in the years 2000 and 2001, as well as questions about perceived general and individual penalization by the opposite sex in the years 2000 and 2001. The concrete question wording is as follows:

- In general, how satisfied are you with your life if 0 means "not at all satisfied" and 10 means "completely satisfied"?

- On a scale from 0 "not at all satisfied" to 10 "completely satisfied" can you indicate your degree of satisfaction with your job generally?

- Do you have the feeling that in Switzerland women are penalized compared with men in certain areas, if 0 means "not at all penalized" and 10 "strongly penalized"?

- Do you, in your everyday life, feel penalized compared with the opposite sex, if 0 means "not at all penalized" and 10 "strongly penalized"?

Answers to these questions are merged with data on the approval of equal rights at the community level.

We assess the possible correlations between our proxy measure for social norms about women's role on the labor market and their subjective wellbeing in two steps. In a descriptive analysis (presented in Table 4), raw correlations are assessed. They include potentially important correlated variation in individual socio-demographic characteristics, such as education. Partial correlations are shown in Table 5.

We first discuss the results for reported satisfaction with life based on a sample of salaried women and men. Descriptive statistics indicate that there is no significant difference in life satisfaction between women and men in communities where a large number of the citizens approved the equal rights amendment (approval rate $>60 \%$ ). In contrast, women working in the labor market are significantly more satisfied with their lives than men in conservative communities (approval rate $<60 \%$ ). This results in a negative difference-indifferences estimation for being a woman and living in a high approval rather than in a low approval community. In Table 5, these findings are replicated in a multiple regression controlling for a large number of individual characteristics (the full estimation results are presented in Table 7 in Appendix). Robust standard errors are reported adjusted for clustering within communities. Like in the previous subsection, the variable measuring the approval of equal rights 


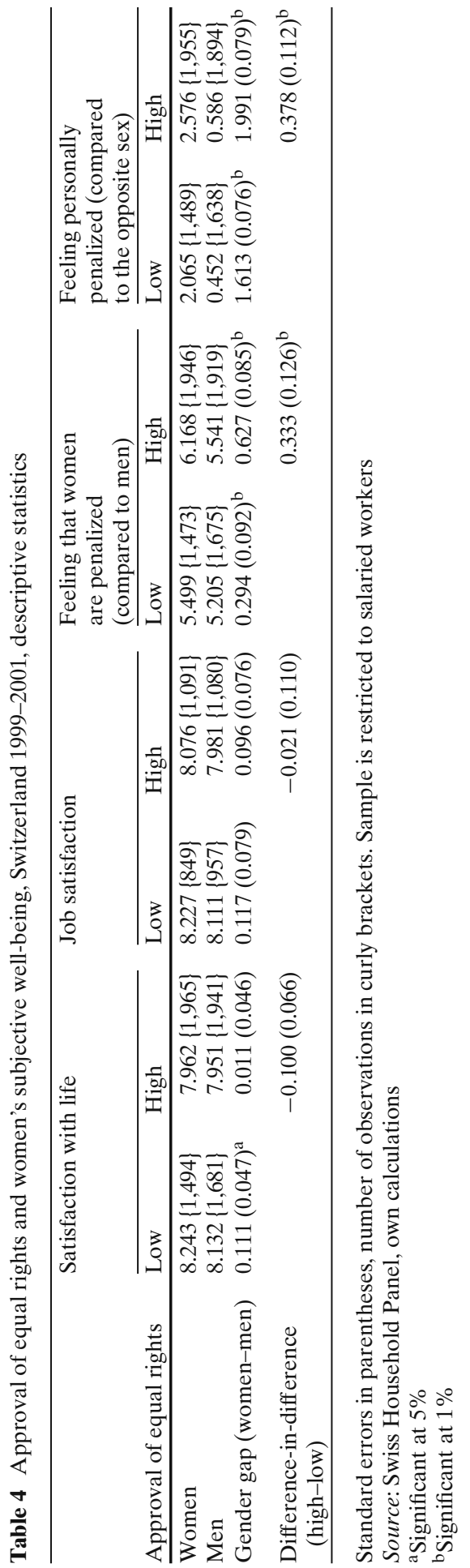


Table 5 Approval of equal rights and women's subjective well-being, Switzerland 1999-2001, partial correlations

\begin{tabular}{|c|c|c|c|c|}
\hline & $\begin{array}{l}\text { Satisfaction } \\
\text { with life }\end{array}$ & Job satisfaction & $\begin{array}{l}\text { Feeling that women } \\
\text { are penalized } \\
\text { (compared to men) }\end{array}$ & $\begin{array}{l}\text { Feeling personally } \\
\text { penalized } \\
\text { (compared to the } \\
\text { opposite sex) }\end{array}$ \\
\hline Female & $0.161(0.047)^{\mathrm{b}}$ & $0.157(0.077)^{\mathrm{c}}$ & $0.422(0.096)^{\mathrm{b}}$ & $1.774(0.093)^{\mathrm{b}}$ \\
\hline $\begin{array}{l}\text { Approval of equal } \\
\text { rights }^{\mathrm{a}}\end{array}$ & $-0.002(0.032)$ & $-0.066(0.048)$ & $0.055(0.058)$ & $-0.051(0.034)$ \\
\hline $\begin{array}{c}\text { Female } \times \text { approval } \\
\text { of equal rights }\end{array}$ & $-0.100(0.037)^{\mathrm{b}}$ & $-0.055(0.059)$ & $0.134(0.078)^{\mathrm{d}}$ & $0.213(0.075)^{\mathrm{b}}$ \\
\hline $\begin{array}{l}\text { Individual } \\
\text { characteristics }\end{array}$ & Yes & Yes & Yes & Yes \\
\hline Observations & 6,203 & 3,383 & 6,149 & 6,114 \\
\hline$R^{2}$ & 0.06 & 0.03 & 0.06 & 0.16 \\
\hline
\end{tabular}

Ordinary least squares estimations. Sample is restricted to salaried workers. Robust standard errors in parentheses (adjusted for clustering within communities)

Source: Swiss Household Panel, own calculations

${ }^{a}$ The approval rate of the equal rights amendment is standardized with a mean of zero and standard deviation equal to one

${ }^{\mathrm{b}}$ Significant at $1 \%$

${ }^{\mathrm{c}}$ Significant at $5 \%$

${ }^{\mathrm{d}}$ Significant at $10 \%$

is standardized to mean zero and standard deviation 1. It is important to note that a respondent's earned income is not included in the estimation function. In order to test whether the variation in the gender wage gap is due to discrimination, the empirical strategy requires to test whether women in communities where they, on average, have lower wages also report lower individual well-being. As lower wages are the theoretically supposed channel through which discrimination works, we have to exclude this variable from the regression. If own labor income were controlled for, the partial correlation between our proxy for the social norm and reported life satisfaction could no longer serve as a test for the discrimination hypothesis. ${ }^{32}$

Results show that employed women, on average, are more satisfied than men, reporting a 0.16 higher score of subjective well-being than employed men. This gender effect is measured at the sample mean of the variable capturing social pay norms. The coefficient for "approval of equal rights" indicates that salaried men are equally satisfied with their life across communities, independent of differences in the social norms for the role of women on the labor market. However, as captured by the interaction term "female $\times$ approval of equal rights," employed women are statistically significantly less satisfied

\footnotetext{
${ }^{32}$ According to the reasoning in the previous section, there are further variables that can be considered endogenous to the norm like education and other household members' income. If these variables are excluded, still a negative partial correlation for the interaction term is estimated (not shown).
} 
with their life in communities where a larger percentage of the population approved equal rights. If the approval rate is increased from one standard deviation below the mean to one standard deviation above the mean, average life satisfaction is reduced by 0.20 units on the ten-point scale. This is a large negative effect, equivalent to having an incomplete compulsory school education rather than having served an apprenticeship, or equal to one seventh of the negative effect of unemployment on life satisfaction..$^{33}$

This result runs contrary to an interpretation of the wage results in the previous section in terms of perceived discrimination in traditional communities.

Before we provide possible interpretations of the findings for the gender wage gap and the life satisfaction gap in more and less liberal communities, we present additional results for women's and men's subjective evaluation of their living situation. As in previous studies, we find higher job satisfaction for women than for men (coefficient for "female" $=0.16$ ). However, we have too small a sample to be able to statistically precisely estimate a partial correlation between the approval of equal rights and regional variation in job satisfaction. So far, a negative coefficient for the interaction variable is estimated.

Tables 4 and 5 include two questions about people's perception of gender discrimination. Contrary to the evidence about the gender wage gap, which is smaller in communities where equal rights have been broadly approved than where there was a lot of opposition, women feel more penalized in more liberal communities than in traditional communities. This result is found in the descriptive statistics as well as in the partial correlations. Moreover, the questions are posed whether people think that women are penalized generally, as well as personally, compared to the opposite sex. Not surprisingly, for both measures, women report higher ratings of being penalized. ${ }^{34}$

A useful unifying framework to understand our results is gender identity (Akerlof and Kranton 2000). Gender is one of the most important social categories. There exist strong gender-specific behavioral prescriptions. As we argue in this paper, an important one is for women to be cooperative, selfless, and modest. On the labor market, this is reflected in lower appropriate wages and reluctance in wage bargaining. Accordingly, utility not only reflects one's own outcomes (i.e., income) but also identity-that is, the extent to which individuals conform to the behavioral prescription of their gender. The identity framework makes predictions that are different from the standard framework in at least two important respects. First, women and men behave differently; in our context, women ask for lower wages than men. Second, gender differences in outcomes need not reflect gender differences in utility.

\footnotetext{
${ }^{33}$ Estimation results including the partial correlation between unemployment and life satisfaction are based on an extended sample of the SHP and can be obtained from the authors on request.

${ }^{34}$ Our results are in line with existing research on the relationship between gender wage gaps and perceived discrimination. Specifically, several authors find that those women reporting the most gender discrimination face, in fact, the least statistical discrimination (Kuhn 1987; Barbezat and Hughes 1990; Antecol and Kuhn 2000).
} 
In this paper, we provide evidence that (1) prescriptions about women's behavior on the labor market differ across space, (2) outcomes vary according to gender prescriptions-gender wage differences are lower in areas favoring prescriptions for equal pay, and (3) self-reported subjective well-being not only depends on outcomes but also on prescriptions for equal pay. These results are in line with a framework stressing gender identity as the source of gender differences in outcomes and seemingly conflicting gender differences in wellbeing. ${ }^{35}$

There are, of course, alternative explanations to the negative correlation between the approval of equal rights and women's satisfaction with life. First, there is the possibility of an omitted variable bias, i.e., a third variable correlated with the measure for the social norm affects the life satisfaction of women and men, but differently. Second, the lower wages of women in more traditional communities could be more than compensated by the higher wages of their husbands. In the main estimation, the partial correlation for the social norm effect (relative to men) is measured for a given income contributed by the partner. In order to exclude this compensatory channel and to measure the net effect for women, the variable capturing other household members' income is dropped in an additional estimation. For this specification, still a negative partial correlation for the interaction term is found. However, consistent with the compensation hypothesis, the coefficient is slightly smaller in absolute terms (not shown). Third, there could be some selection effect that leads happy women in traditional communities to go for paid work, while the unhappy women stay at home. However, an empirical test looking at the partial correlation between the measure for the social norm and the subjective wellbeing of women who are not in salaried employment is not consistent with this explanation (results not shown). Fourth, women in liberal communities might just be the precursors of a movement that tries to change traditional norms about women's restricted role on the labor market. This "revolt" may have some gains in terms of higher salaries, but might result in even higher costs due to the social sanctions by traditional women and men. Moreover, it might well be that equality at the work place has developed substantially in more liberal communities, as reflected by the lower gender wage gap. However, working women may still have to carry most of the burden of doing the housework.

\section{Concluding remarks}

It is well known that women earn less than men. However, women are not less satisfied with their jobs or with their lives than men. This paper argues that the extent to which women and men believe that a woman's appropriate

\footnotetext{
${ }^{35}$ Another test of the gender identity hypothesis based on data on reported subjective well-being is by Booth and van Ours (2008). They relate intra-family patterns in working hours to spouses' life satisfaction.
} 
salary is equal to a man's salary may be important in understanding this puzzle. Historically, women and men tended to specialize in different areas of life, with men being responsible for the family income and women being responsible for the well-being of the family.

This paper captures the extent to which such gender-specific norms still apply today with the voting outcome regarding an equal rights amendment to the Swiss constitution in 1981. The approval rate for the equal rights amendment, prescribing "equal pay for equal work," varies very strongly across communities. Thus, it is possible to assess the relevance of genderspecific pay norms for the relative success of women and men on the labor market by linking the gender wage gap measured for the years 1991-2003 to the voting outcome. Results indicate that the mean gender wage gap is narrowed by as much as one sixth due to an increase of one standard deviation in the approval of equal rights. Moreover, there is no corresponding effect in the public sector, which applies standardized compensation rules and was covered by non-discriminatory legislation as early as 1977 .

As wage differences may not capture the full extent to which women's lives are affected by gender-specific pay norms and prescriptions about appropriate behavior on the labor market, we study self-reported subjective well-being for 2000/2001. Results indicate that in contrast to an explanation based on perceived discrimination, women in conservative areas (with strong disapproval of equal rights and a large gender wage gap) are more (not less) satisfied with their life than men. There is no corresponding difference between women and men in liberal areas. This result reinforces the interpretation based on genderspecific identity and internalized norms regarding appropriate pay for women compared to men.

Based on the evidence, we conclude that social norms regarding appropriate pay for women and men are the main explanatory factor of current gender differences in economic well-being. This explanation implies that changing the outcomes for women will take a long time. While our study offers an important first step towards understanding the overall implications of gender pay norms, we believe that future work should address exactly how norms and institutions interact and thus study the dynamics in social norm changes. Primarily, we shall address how anti-discrimination law affects women's behavior and well-being, given their varying liberal views, and how their actual beliefs are affected.

Acknowledgements We are grateful to two anonymous referees, George Akerlof, Bruno S. Frey, Ed Glaeser, Lorenz Götte, Andreas Kuhn, Audrey Light, Simon Lüchinger, Stephan Meier, Tuomas Pekkarinen, Dina Pomeranz, Betsey Stevenson, Josef Zweimüller, and participants at the 1st International Panel User Conference in Switzerland, EALE, the IZA Workshop on "The Nature of Discrimination", the Annual Meeting of the German Economic Association, the Annual Meeting of the American Economic Association, the Annual Congress of the Swiss Society of Economics and Statistics, the Annual Meeting of the European Public Choice Society, and the research seminar at the University of Würzburg for helpful comments and to Andreas Herzog for the use of mapresso. This study has been realized using the data collected by the Swiss HouseholdPanel, a project financed by the Swiss National Science Foundation Program, SPP, "Switzerland Towards the Future" (grant no. 5004-53205). 


\section{Appendix}

Table 6 Approval of equal rights and wages, Switzerland 1999-2003, dependent variable: log (hourly wage rate)

\begin{tabular}{ll}
\hline Female & $-0.138(0.006)^{* * *}$ \\
Approval of equal rights ${ }^{\mathrm{a}}$ & $0.035(0.006)^{* * *}$ \\
Female $\times$ approval of equal rights & $0.024(0.006)^{* * *}$ \\
Schooling (in years) & $0.070(0.002)^{* * * *}$ \\
Work experience (in years) & $0.024(0.001)^{* * *}$ \\
Work experience squared/100 & $-0.040(0.002)^{* * *}$ \\
Tenure (in years) & $0.012(0.001)^{* * *}$ \\
Tenure squared/100 & $-0.020(0.002)^{* * *}$ \\
Non-Swiss & $-0.098(0.007)^{* * *}$ \\
Married & $0.080(0.006)^{* * *}$ \\
Part-time & $-0.043(0.008)^{* * *}$ \\
Canton effects & Yes \\
Year effects & Yes \\
Observations & 117,878 \\
$R^{2}$ & 0.30 \\
\hline
\end{tabular}

Results are not shown for year dummies, dummies indicating that work income or the level of education is not known and dummies for interview language. Robust standard errors adjusted for clustering within communities are reported in parentheses. ***Significant at $1 \%$

Source: Swiss Labor Force Survey, own calculations

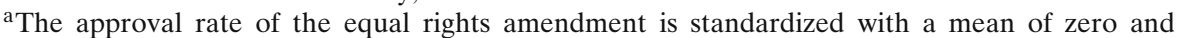
standard deviation equal to one

Table 7 Approval of equal rights and life satisfaction, Switzerland 2000-2001, dependent variable: satisfaction with life

\begin{tabular}{|c|c|c|c|c|}
\hline & \multicolumn{2}{|l|}{ OLS } & \multicolumn{2}{|c|}{ Ordered probit } \\
\hline & Coef. & Robust SE & Coef. & Robust SE \\
\hline Female & 0.161 & 0.048 & 0.142 & 0.037 \\
\hline Approval of equal rights ${ }^{\mathrm{a}}$ & -0.002 & 0.032 & -0.003 & 0.025 \\
\hline Female $\times$ approval of equal rights & -0.100 & 0.037 & -0.074 & 0.028 \\
\hline Age & -0.078 & 0.014 & -0.065 & 0.011 \\
\hline Age squ./100 & 0.094 & 0.016 & 0.079 & 0.013 \\
\hline Compulsory schooling & \multicolumn{4}{|c|}{ Reference group } \\
\hline Incomplete compulsory schooling & -0.096 & 0.661 & 0.123 & 0.411 \\
\hline Apprenticeship & 0.121 & 0.081 & 0.056 & 0.060 \\
\hline Maturity/high school & 0.179 & 0.090 & 0.093 & 0.069 \\
\hline Vocational high school & 0.244 & 0.094 & 0.139 & 0.074 \\
\hline University of applied sciences & 0.264 & 0.111 & 0.147 & 0.086 \\
\hline University & 0.265 & 0.088 & 0.152 & 0.067 \\
\hline Single & \multicolumn{4}{|c|}{ Reference group } \\
\hline Married & 0.334 & 0.069 & 0.273 & 0.056 \\
\hline Separated & -0.654 & 0.223 & -0.384 & 0.142 \\
\hline Divorced & -0.191 & 0.106 & -0.110 & 0.080 \\
\hline Widowed & 0.001 & 0.200 & -0.003 & 0.169 \\
\hline National & \multicolumn{4}{|c|}{ Reference group } \\
\hline Foreigner & -0.367 & 0.067 & -0.264 & 0.051 \\
\hline
\end{tabular}


Table 7 (continued)

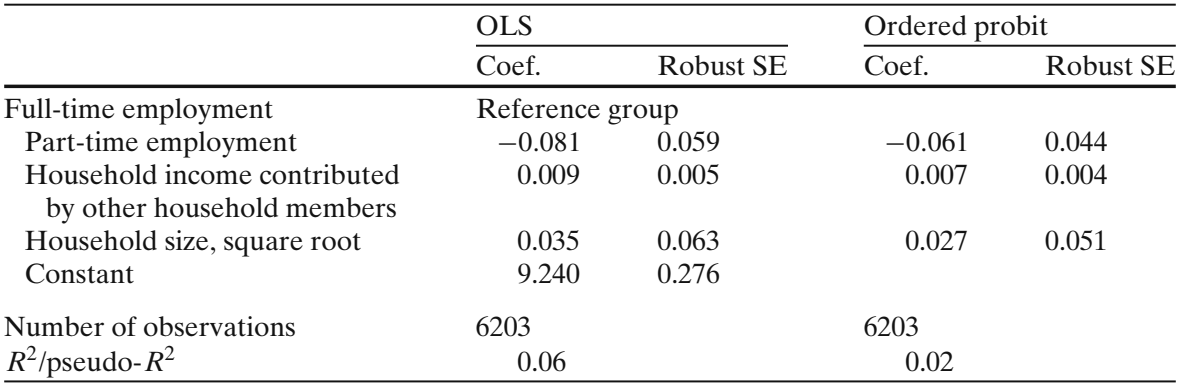

Results are not shown for year dummy, dummies indicating that work income or the level of education is not known and dummies for interview language

Source: Swiss Household Panel, own calculations

${ }^{\text {a }}$ The approval rate of the equal rights amendment is standardized with a mean of zero and standard deviation equal to one

\section{References}

Akerlof GA, Kranton RE (2000) Economics and identity. Q J Econ 115(3):715-753

Albrecht J, Bjorklund A, Vroman S (2003) Is there a glass ceiling in Sweden? J Labor Econ 21(1):145-177

Altonji JG, Blank RM (1999) Race and gender in the labor market. In: Ashenfelter O, Card D (eds) Handbook of labor economics, vol 3C. Elsevier Science, Amsterdam, pp 3143-3259

Antecol H, Kuhn P (2000) Gender as an impediment to labor market success: why do young women report greater harm? J Labor Econ 18(4):702-728

Babcock L, Laschever S (2003) Women don't ask. Negotiation and the gender divide. Princeton University Press, Princeton

Barbezat DA, Hughes JW (1990) Sex discrimination in labor markets: the role of statistical evidence: comment. Am Econ Rev 80(1):277-286

Becker GS (1976) The economic approach to human behavior. University of Chicago Press, Chicago

Bewley TE (1999) Why wages don't fall during a recession. Harvard University Press, Cambridge

Black SE, Strahan PE (2001) The division of spoils: rent-sharing and discrimination in a regulated industry. Am Econ Rev 91(4):814-831

Blanchflower DG, Oswald AJ (2004) Well-being over time in Britain and the USA. J Public Econ 88(7-8):1359-1386

Blau FD, Kahn LM (1992) The gender earnings gap: learning from international comparisons. Am Econ Rev 82(2):533-538

Blau FD, Kahn LM (2000) Gender differences in pay. J Econ Perspect 14(4):75-99

Blau FD, Kahn LM (2003) Understanding international differences in the gender pay gap. J Labor Econ 21(1):106-144

Bonjour D, Gerfin M (2001) The unequal distribution of unequal pay-an empirical analysis of the gender wage gap in Switzerland. Empir Econ 26(2):407-428

Booth AL, van Ours JC (2008) Hours of work and gender identity: does part-time work make the family happier? Economica 76(301):176-196

Bylsma WH, Major B (1992) Two routes to eliminating gender differences in personal entitlement: social comparisons and performance evaluations. Psychol Women Q 16(2):193-200

Bylsma WH, Major B (1994) Social comparisons and contentment: exploring the psychological costs of the gender wage gap. Psychol Women Q 18(2):241-249

Callahan-Levy CM, Messe LA (1979) Sex differences in the allocation of pay. J Pers Soc Psychol 37(3):433-446 
Clark AE (1997) Job satisfaction and gender: why are women so happy at work? Labour Econ 4(4):341-372

Clark AE, Oswald AJ (1996) Satisfaction and comparison income. J Public Econ 61(3):359-381

Crosby FJ (1982) Relative deprivation and working women. Oxford University Press, New York

Davenport HJ (1919) Wage theory and theories. Q J Econ 33(2):256-297

Fehr E, Gächter S (2000) Fairness and retaliation: the economics of reciprocity. J Econ Perspect 14(3):159-181

Flückiger Y, Ramirez J (2000) Auf dem Weg zur Lohngleichheit? Eidgenössisches Büro für die Gleichstellung für Mann und Frau, Bern

Frey BS, Stutzer A (2002a) Happiness and economics: how the economy and institutions affect human well-being. Princeton University Press, Princeton

Frey BS, Stutzer A (2002b) What can economists learn from happiness research? J Econ Lit 40(2):402-435

Frey BS, Benz M, Stutzer A (2004) Procedural utility: not only what, but also how matters. J Inst Theor Econ 160(3):377-401

Jann B (2003) Lohngerechtigkeit und Geschlechterdiskriminierung: experimentelle evidenz. Mimeo, ETH Zurich

Jasso G, Webster M Jr (1997) Double standards in just earnings for male and female workers. Soc Psychol Q 60(1):66-78

Kahneman D (2000) Experienced utility and objective happiness: a moment-based approach. In: Kahneman D, Tversky A (eds) Choices, values and frames. Cambridge University Press, New York

Kuhn PJ (1987) Sex discrimination in labor markets: the role of statistical evidence. Am Econ Rev 77(4):567-583

Major B, McFarlin DB, Gagnon D (1984) Overworked and underpaid: on the nature of gender differences in personal entitlement. J Pers Soc Psychol 47(6):1399-1412

Manning A (2003) The real thin theory: monopsony in modern labour markets. Labour Econ 10(2):105-131

Nolen-Hoeksema SK, Rusting C (1999) Gender differences in well-being. In: Kahneman D, Diener E, Schwarz N (eds) Foundations of hedonic psychology. Russell Sage Foundation, New York, pp 330-352

Phelan J (1994) The paradox of the contented female worker: an assessment of alternative explanations. Soc Psychol Q 57(2):95-107

Ransom M, Oaxaca R (2005) Sex differences in pay in a "new monopsony" model of the labor market. IZA Discussion Paper no 1870. IZA, Bonn

Reis H (1988) Die Lohndifferenzen zwischen Männern und Frauen in der Schweiz. Peter Lang, Bern

Riley H, McGinn KL (2002) When does gender matter in negotiation? John F. Kennedy School of Government, Harvard University, Faculty Research Working Paper no 36, Harvard

Säve-Söderbergh J (2006) Are women asking for low wages? An empirical analysis of individual wage bargaining and ability signaling. Stockholm University Working Paper, Stockholm

Solnick SJ (2001) Gender differences in the ultimatum game. Econ Inq 39(2):189-200

Sousa-Poza A, Sousa-Poza AA (2000) Taking another look at the gender/job-satisfaction paradox. Kyklos 53(2):135-152

Sousa-Poza A, Sousa-Poza AA (2003) Gender differences in job satisfaction in Great Britain, 1991-2000: permanent or transitory? Appl Econ Lett 10(11):691-694

Stanley TD, Jarrell SB (1998) Gender wage discrimination bias? A meta-regression analysis. J Hum Resour 33(4):947-973

Stevenson B, Wolfers J (2007) The paradox of declining female happiness. Mimeo, The Wharton School, University of Pennsylvania, Pennsylvania

Stuhlmacher AF, Walters AE (1999) Gender differences in negotiation outcome: a meta-analysis. Pers Psychol 52(3):653-677

Stutzer A (2004) The role of income aspirations in individual happiness. J Econ Behav Org 54(1):89-109

Stutzer A, Lalive R (2004) The role of social work norms in job searching and subjective wellbeing. J Eur Econ Assoc 2(4):696-719 
Wade ME (2001) Women and salary negotiation: the costs of self-advocacy. Psychol Women Q 25(1):65-76

Webb S (1891) The alleged differences in the wages paid to men and to women for similar work. Econ J 1(4):635-662

Weichselbaumer D, Winter-Ebmer R (2005) A meta-analysis of the international gender wage gap. J Econ Surv 19(3):479-511 